\title{
US cancer trials may go the way of the Oldsmobile
}

\author{
David Dilts
}

Cancer clinical trials in the US are at a major crossroads. Current government-sponsored research is some of the best in the world, but the field shares a worrying number of similarities with the American auto industry in its heyday. For clinical research to survive, the field must transform itself now to prevent a similar decline.

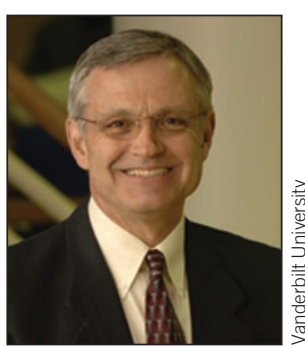

In 1955, General Motors (GM) was the world's single largest employer. That same year, the US National Cancer Institute (NCI) launched its clinical trials cooperative group program aimed at assembling researchers, physicians and academic medical centers to collectively bring new therapies to the clinic. GM and the cooperative group program both revolutionized the landscape of their respective fields: the auto giant created new products and a new way of doing business, and the cooperative group program completed ground-breaking and practicechanging clinical trials. But times have changed since 1955.

The cooperative group program was enacted to expedite the development of promising anticancer therapies through large-scale trials in multi-institutional settings. In the beginning, it did so with speed and agility, but the system has become bogged down in repeated and redundant steps, processing loops and interactions between various organizations and agencies.

Today, the average time involved to take a new therapeutic compound from discovery to commercialization in the US is nearly 13 years, up from less than eight years in the $1960 \mathrm{~s}^{1}$. By comparison, in the 1980s and 1990s the 'Big Three' American automobile manufacturers-GM, Ford and Chrysler - cut the time needed to design, engineer and market a new car from five years to three years, whereas their Japanese counterparts can now complete the same set of activities in less than half that time ${ }^{2}$.

To uncover the extent of the problem in clinical development, my colleagues and I dissected the processes required to develop and launch a phase 3 therapeutic cancer trial under the cooperative group umbrella. We found that designing and opening a single trial requires hundreds of processing steps in multiple organizations, dozens of points where a potential study can be returned to earlier steps for revision (we term them 'loops') and dozens of individual or group approvals. Our forthcoming data show that navigating this system requires a median of approximately 2.5 years-and this is only to open the study for patient accruals, not to complete the trial ${ }^{3}$.

Although there are myriad factors involved, one of the key differences between automobile and new drug development is that stakeholders involved in the former have investigated the time required to complete all steps required to bring a product to market. But in drug development, particularly trials sponsored by the government, only some of the steps have been formally documented and researched, and many major additional, 'hidden' infrastructural barriers remain ${ }^{4}$.

So how do clinical researchers reduce the lengthy process involved in launching human trials? Motivated by this question, the NCI and the US Institute of Medicine (IOM) asked me to join independent committees to help craft two recent reports on the operational issues of clinical research. The reports, released in $\mathrm{March}^{5}$ and April ${ }^{6}$, set compulsory timelines to opening various phase trials and stressed, among other things, the need to consolidate functions within the cooperative group system and to streamline oversight. Recommendations from both reports, if adopted, will make considerable strides in the much-needed reengineering of this system.

Money is also clearly a problem. For example, cooperative groups' budgets and the $\$ 2,000$ per patient reimbursement have remained constant since the turn of the millennium. However, simply adding money to the cooperative group program will not assure better or faster trial development. Using data collected from one cooperative group, my team simulated what would occur to the development cycle if we doubled the infrastructure budget at the cooperative group level. The result was a negligible difference in the time needed to open a trial.

The primary reason for this poor improvement is that cooperative groups cannot develop and open trials on their own. Instead, cooperative groups must work directly with many different stakeholders, including specialized committees at individual institutions, the NCI Cancer Therapy Evaluation Program (CTEP) that coordinates and oversees the cooperative group program and, often, pharmaceutical companies that supply study drugs. Because each evaluation must be reviewed by the other committees, nearly endless loops can be created, and the issue of time becomes problematic and exponential.

The same could be said of the old-style American auto industry. Despite the inroads made in cutting development time, the Big Three maintained cumbersome hierarchies and inefficient systems, especially when compared to foreign competition, who could rapidly deploy innovations. This delay, in part, led to the demise of GM's Oldsmobilewhich went from the top-selling car in the country in 1976 to a brand that was discontinued less than 30 years later-not to mention the entire US car industry, which nearly came crashing down last year.

What's more, just as US car buyers are increasingly purchasing brands made overseas, drug companies are also moving to outsource their clinical trials. For example, a recent report found that the majority of study sites in industry-sponsored phase 3 clinical trials are now located outside the US $^{7}$. To keep up with growing international competition, those in and responsible for the cooperative group program must transition from reports and recommendations to actions.

In oncology alone, with more than 1.3 million new cases of cancers diagnosed and over 550,000 deaths annually, it's unconscionable that it can take years to open trials that could be started up in weeks. It's time to apply the lessons learned from the auto industry to dramatically reduce the barriers to clinical trials-lest oncology trials in the US follow the path of the Oldsmobile.

David Dilts is the director of the Center for Management Research in Healthcare at the Oregon Health \& Science University's Knight Cancer Institute in Portland. A management scientist by training, Dilts was a member of the IOM's committee on cancer cooperative groups and the NCI's Operational Efficiency Working Group. The views expressed are his own and do not reflect the position of any affiliate institutions.

1. Dickson, M. \& Gagnon, J.P., Nat. Rev. Drug Discov. 3, 417-429, (2004).

2. Adams, W. \& Brock, J. The bigness complex. 52 (Stanford University Press. 2004),

3. Dilts D.M., Cheng, S., Crites, J., Sandler, A. \& Doroshow, J. Clin. Cancer Res., doi: 10.1158/1078-0432.ccr-10-1273, 2010.

4. Dilts, D.M. \& Sandler, A.B. J. Clin. Oncol. 24, 4545-4552 (2006).

5. Operational Efficiency Working Group of the Clinical Trials and Translational Research Advisory Committee. Compressing the Timeline for Cancer Clinical Trial Activation. http://ccct.cancer.gov/files/OEWG-Report.pdf (2010).

6. Institute of Medicine. A National Cancer Clinical Trials System

for the 21st Century. http://books.nap.edu/openbook.php?record_id=12879 (2010).

7. Glickman, S.W. et al. N. Engl. J. Med. 360, 816-823 (2009), 